\title{
Evaluation of c-Met, HGF, and HER-2 expressions in gastric carcinoma and their association with other clinicopathological factors
}

This article was published in the following Dove Press journal:

OncoTargets and Therapy

22 September 2016

Number of times this article has been viewed

\section{Yetkin Yıldız' \\ Cenk Sokmensuer ${ }^{2}$ \\ Suayib Yalcin' \\ 'Department of Medical Oncology, ${ }^{2}$ Department of Pathology, Hacettepe University, Ankara, Turkey}

Background: Met and HER-2 are proto-oncogenes encoding receptor tyrosine kinase c-Met and HER-2, respectively. Hepatocyte growth factor (HGF) is a ligand of c-Met. The frequency of c-Met, HGF, and HER-2 expressions in gastric cancer and their association with other clinicopathological factors have not been fully understood.

Patients and methods: Patients with stage 1-4 disease were analyzed. Expressions of c-Met, HGF, and HER-2 were examined using immunohistochemistry.

Results: A total of 143 patients, 97 males and 46 females, were included. C-Met scores were 3(+) in $31.5 \%, 2(+)$ in $27.3 \%$, and $1(+)$ in $10.5 \%$ of the patients. There was no statistically significant difference in age, sex, tumor location, differentiation, Lauren classification, TNM staging, presence of distant metastasis, depth of tumor invasion ( $\mathrm{T}$ ), lymphovascular invasion, and survival between c-Met subgroups. Overall HGF positivity was 20.6\%. HER-2 scores were $3(+)$ in $9.1 \%$, $2(+)$ in $9.8 \%$, and $1(+)$ in $16.1 \%$ of the patients. HER-2 overexpression was associated with better differentiation, intestinal subtype, and advanced stage. C-Met overexpressions were $84.6 \%$ in the HER-2-overexpression-positive group and 56.2\% in the HER-2-overexpression-negative group. There were no statistically significant differences in survival between the high c-Met-expressionpositive and -negative stage 3 and stage 4 patients and between the HGF-positive and -negative groups. The mean survival was 11.6 \pm 6.3 months in the HER-2-overexpression-positive stage 4 group and 11.9 \pm 6.8 months in the HER-2-overexpression-negative stage 4 group. There were no statistically significant differences in survival between the two groups.

Conclusion: c-Met was not associated with any prognostic factors in gastric cancer. HER-2 was associated with better differentiation, intestinal subtype, advanced stage, and c-Met overexpression.

Keywords: gastric cancer, HER-2, c-Met, HGF, clinicopathological features, prognostic factors
Correspondence: Suayib Yalcin Department of Medical Oncology, Hacettepe University Institute of Cancer, Sihhiye, Ankara 06100, Turkey

Tel +90312305294 I

$\mathrm{Fax}+903123092024$

Email syalcin@hacettepe.edu.tr

\section{Introduction}

The incidence and mortality of gastric cancer, which was once the most common cancer worldwide, are decreasing, due to a drop in the rate of distal gastric cancer in the Western world. ${ }^{1}$ However, despite advances in diagnosis and treatment, gastric cancer has a very poor prognosis, and the 5 -year survival rate of stomach cancer is only $20 \%$. The etiology of gastric cancer is multifactorial and includes both dietary and nondietary factors. ${ }^{2}$ Gastric cancer is the second leading cause of cancer deaths in men and the third in women. The development of gastric cancer is a complex, multistep process involving multiple genetic and epigenetic alterations of oncogenes, tumor suppressor genes, DNA repair genes, cell cycle regulators, and signaling molecules. ${ }^{2}$ There is a need to identify new therapeutic targets to be used in the treatment of gastric cancer. 
Receptor tyrosine kinases (RTKs) consist of ligandbinding extracellular domains that identify the subfamilies of RTKs, a transmembrane domain and a tyrosine kinase part. ${ }^{3}$ The RTK c-Met is encoded by MET oncogene. This receptor and its hepatocyte growth factor (HGF) ligand pathway stimulate the proliferation, invasion, angiogenesis, and protection of cancer cells from apoptosis. ${ }^{4}$ High c-Met expression has been reported in a number of cancers, including lung, colorectal, prostate, pancreatic, head and neck, gastric, hepatocellular, ovarian, and renal cancers and glioma, melanoma, and a number of sarcomas. ${ }^{5}$ The observed median proportions of high c-Met expression were 59\% (range 26\%-82\%) and 16\% (range 8\%-29\%), respectively, in studies using immunohistochemistry (IHC) and other methods. ${ }^{4}$ The findings of current literature on c-Met overexpression and its relationship with prognosis and other clinicopathological variables are controversial. Some studies have demonstrated no relationships between c-Met overexpression and other clinicopathological variables. ${ }^{6,7}$ However, some other studies have reported a strong relationship between c-Met overexpression and tumor invasion depth (T), lymph node metastasis, survival, and intestinal-type tumors. ${ }^{89}$ Increased expression of HGF and c-Met has been linked to poor prognosis and prediction of peritoneal dissemination. ${ }^{10}$

HER-2 is a member of the human epidermal growth factor receptor family. ${ }^{11}$ It is the product of the human HER-2 gene weighing $185 \mathrm{kDa}$ with tyrosine kinase activity. ${ }^{12}$ This RTK protein regulates signal transduction that is important for cell proliferation, differentiation, and survival. ${ }^{11}$ Overexpression of HER-2 is a frequent molecular event in multiple human cancers, including breast, ovarian, pulmonary, colorectal, and gastric carcinomas. ${ }^{13,14}$ The rate of HER-2 overexpression varies in different gastric carcinoma studies. The rate of HER-2 overexpression has been reported to be between $5 \%$ and $62 \%$ in different studies. ${ }^{15}$ ToGA clinical trial showed that the humanized monoclonal antibody against HER-2, trastuzumab (Herceptin), could effectively prolong overall survival and progression-free survival and increase the response rate in HER-2-positive advanced gastric carcinoma. ${ }^{11}$

Other molecules have also been investigated for their role in tumor growth and as a target for treatment, such as c-Met. In the present study, we aimed to determine the frequency of c-Met, HGF, and HER-2 overexpression in gastric cancer and their association with prognosis and clinicopathological factors.

\section{Patients and methods}

\section{Patients}

Gastric cancer patients diagnosed between the years 2006 and 2011 were included. Hospital files and hospital database system were retrospectively analyzed. A total of 150 patients whose pathology slides were available and evaluable in Hacettepe University Hospital were enrolled. Patients were evaluated for age, sex, tumor location, tumor differentiation, Lauren classification, tumor node metastasis (TNM) stage (by seventh Union for International Cancer Control/American Joint Committee on Cancer), distant metastases, depth of tumor invasion (T), lymphovascular invasion, peritoneal carcinomatosis, and survival using medical records. If Lauren classification, differentiation, and lymphovascular invasion information were not reported, the slides of these patients were evaluated again to gather this information. The patients who died just after surgery and did not receive a standard therapy or those patients whose information was missing were not included in the survival analyses. The study protocol was reviewed and approved by the Institutional Ethics Committee of Hacettepe University Faculty of Medicine. This is retrospective translational research and written consent is not required and also not available because most or the patients died at the time of the study.

\section{Tissue samples, IHC, and evaluation of immunohistochemical staining}

Ten percentage of formalin-fixed and paraffin-embedded surgical or endoscopic tumor sample blocks were selected. After fixation, tumor samples were embedded in paraffin. Then, tumor sample slides with a $4 \mu \mathrm{m}$ thickness were prepared from paraffin blocks. Immunohistochemical staining was performed using an automatic immunostainer (Ventana Medical Systems, Inc., AZ, USA). Slides were deparaffinized in xylene for 20 minutes. Antigen retrieval time was 90 minutes for c-Met, 30 minutes for HER-2, and 60 minutes for HGF antibodies. After titrating the primary antibody for 2 hours, amplification was carried out, counterstained with hematoxylin for 8 minutes and then incubated with bluing reagent for 4 minutes. When the slides were taken out of the automatic immunostainer, they were washed in $70 \%$ alcohol for 5 minutes, $80 \%$ alcohol for 5 minutes, and $100 \%$ alcohol for 5 minutes; treated with xylene; left undisturbed for 10 minutes; and then kept at room temperature. After the slides dried, they were covered with ethylene. Lyophilized mouse monoclonal antibodies for HER-2 (novocastra) with an optimal dilution of $1 / 800$, c-Met (novocastra) with an optimal dilution of $1 / 30$, and HGF with an optimal dilution of 1/25 were used. Human breast, prostate, and tonsil tissues were used as positive control for, respectively, HER-2, c-Met, and HGF antibody. Each tissue sample was evaluated and scored by one pathologist who was blind to patients' data. A pathologist reported c-Met expression as the cytoplasmic 
Table I c-Met scoring system according to membranous and cytoplasmic c-Met staining patterns

\begin{tabular}{ll}
\hline Staining pattern & Score \\
\hline Membranous 3+ staining, cytoplasmic negative, I+, 2+, or 3+ & 3 \\
staining; membranous 2+ and cytoplasmic 2+, I+ or negative & \\
staining; cytoplasmic 3+ and membranous negative, I+, 2+ or & \\
3+ staining & \\
Membranous I+ and cytoplasmic 2+ staining; cytoplasmic 2+ & 2 \\
and membranous negative staining & \\
Membranous I+ and cytoplasmic I+ or negative staining & I \\
Membranous negative and cytoplasmic I+ or negative staining & 0 \\
\hline
\end{tabular}

and membranous staining intensity from 0 to $3+$ (Table 1 ).

HGF expression has been graded as positive or negative according to the presence of cytoplasmic staining intensity at $10 \times$ microscopical examination. c-Met overexpression is defined as intensity 2 or $3(+)$ staining. HER-2 immunohistochemical scoring was done according to the scoring system suggested by Hofmann et al. ${ }^{16}$ Staining intensity of $3+$ score was accepted as overexpression.

\section{Statistical analyses}

All statistical analyses were performed using the SPSS software Version 18 (SPSS Inc., Chicago, IL, USA). Quantitative data are presented as mean $\pm \mathrm{SD}$. The Chi-square, Fisher's exact test, or Mann-Whitney $U$-test, where appropriate, was used to compare the proportions in different groups. $P$-value $<0.05$ was considered to be significant. Kaplan-Meier method was used for survival analysis, and comparisons between different subgroups were performed using the log-rank test.

\section{Results}

Paraffin tumor blocks of 150 gastric cancer patients were achieved but clinical information of seven cases were missing. Finally, 143 cases, 97 males and 46 females, were included. The mean age was $57.3 \pm 13.1$ (range $28-90$ years). C-Met scores were $3(+)$ in $31.5 \%, 2(+)$ in $27.3 \%$, and $1(+)$ in $10.5 \%$ and negative in $30.8 \%$ of the patients. C-Met expression $(2+$ and $3+$ ) rate was $58.7 \%(84 / 143)$. HER-2 scores were $3(+)$ in $9.1 \%, 2(+)$ in $9.8 \%, 1(+)$ in $16.1 \%$, and negative in $65.0 \%$ of the patients. HGF was positive in $20.6 \%$ and negative in $79.4 \%$ of the patients ( $\mathrm{n}=126$; Table 2$)$. The median overall survival was $21.2 \pm 3.8$ months in 102 patients who were included in the survival analysis (Figure 1).

\section{C-Met staining report}

Of the 143 gastric carcinoma tissue samples, $44(30.8 \%)$ were scored as $0,15(10.5 \%)$ as $1(+), 39(27.2 \%)$ as $2(+)$, and $45(31.5 \%)$ as $3(+)$. The overexpression $(2+$ and $3+)$
Table 2 General features of the patients and CMET, HER-2, and HGF staining results

\begin{tabular}{|c|c|c|}
\hline $\begin{array}{l}\text { Clinicopathological } \\
\text { factors }\end{array}$ & $\begin{array}{l}\text { Patients, } n \\
(n=143)\end{array}$ & $\%$ \\
\hline Age (years) & $57.3 \pm 13.1$ & \\
\hline \multicolumn{3}{|l|}{ Sex } \\
\hline Male & 97 & 67.8 \\
\hline Female & 46 & 32.2 \\
\hline \multicolumn{3}{|l|}{ Tumor location } \\
\hline Proximal & 29 & 20.3 \\
\hline Distal & 100 & 69.9 \\
\hline Diffuse & 14 & 9.8 \\
\hline \multicolumn{3}{|l|}{ Tumor differentiation } \\
\hline Well & 16 & 11.2 \\
\hline Moderate & 40 & 28.0 \\
\hline Poor & 87 & 60.8 \\
\hline \multicolumn{3}{|l|}{ Lauren classification } \\
\hline Diffuse & 45 & 31.5 \\
\hline Intestinal & 71 & 49.7 \\
\hline Mix & 27 & 18.9 \\
\hline \multicolumn{3}{|l|}{ Tumor stage (TNM) } \\
\hline I & 9 & 6.3 \\
\hline 2 & 22 & 15.4 \\
\hline 3 & 62 & 43.4 \\
\hline 4 & 50 & 35.0 \\
\hline \multicolumn{3}{|l|}{ Distant metastasis } \\
\hline Positive & 50 & 35.0 \\
\hline Negative & 93 & 65.0 \\
\hline Depth of invasion $(T)$ & $n=120$ & \\
\hline PTI & 7 & 5.8 \\
\hline pT2 & 7 & 5.8 \\
\hline $\mathrm{pT} 3$ & 26 & 21.7 \\
\hline $\mathrm{pT} 4$ & 80 & 66.7 \\
\hline Lymphovascular invasion & $n=120$ & \\
\hline Positive & 106 & 88.3 \\
\hline Negative & 14 & 11.7 \\
\hline \multicolumn{3}{|l|}{ c-Met expression } \\
\hline Negative & 44 & 30.8 \\
\hline $\mathrm{I}+$ & 15 & 10.5 \\
\hline $2+$ & 39 & 27.3 \\
\hline $3+$ & 45 & 31.5 \\
\hline Overexpression (2+ vs 3+) & 84 & 58.7 \\
\hline \multicolumn{3}{|l|}{ HER-2 expression } \\
\hline Negative & 93 & 65.0 \\
\hline $\mathrm{I}+$ & 23 & 16.1 \\
\hline $2+$ & 14 & 9.8 \\
\hline $3+$ (overexpression) & 13 & 9.1 \\
\hline HGF expression & $n=126$ & \\
\hline Negative & 100 & 79.4 \\
\hline Positive & 26 & 20.6 \\
\hline \multirow[t]{2}{*}{ Survival (months) } & $n=102$ & \\
\hline & $21.2 \pm 3.8$ & \\
\hline
\end{tabular}

Abbreviation: HGF, hepatocyte growth factor.

rate was $58.7 \%$ (84/143; Figure 2). The c-Met status was not associated with the sex, tumor location, tumor differentiation, Lauren classification, TNM stage (by seventh UICC/AJCC), presence or absence of distant metastases, depth of tumor invasion (T), and lymphovascular invasion 


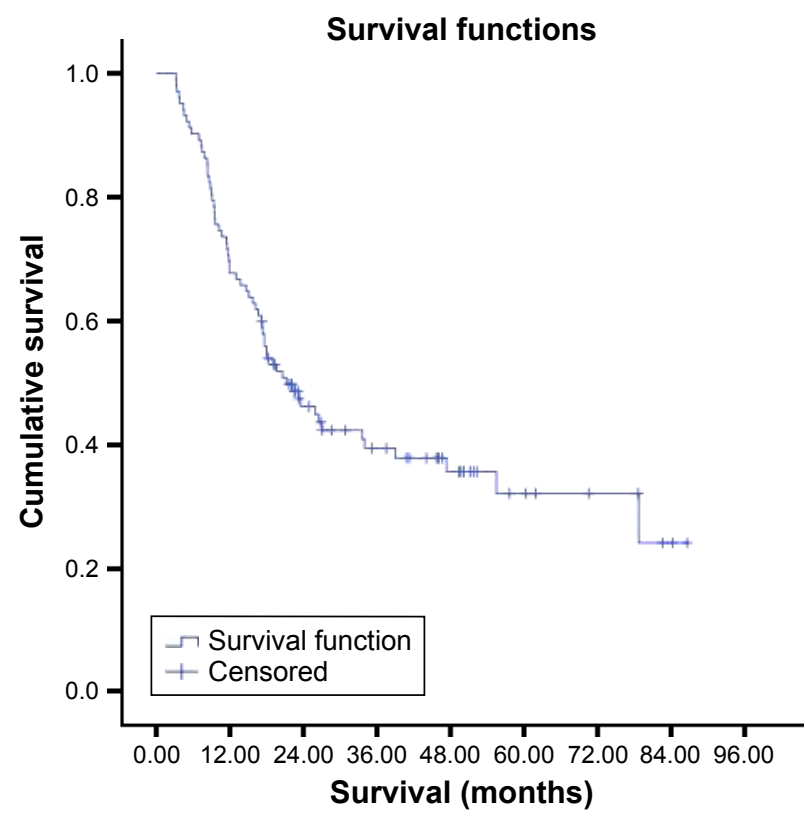

Figure I Survival curve of all patients.

Note: The median overall survival was 21.2 months in 102 patients who were included in survival analysis.

$(P=0.462, P=0.595, P=0.636, P=0.387, P=0.823, P=0.823$, $P=0.820$, and $P=0.678$ ). HER-2 overexpression was $13.1 \%$ in the c-Met-overexpression-positive group and $3.4 \%$ in the c-Met-overexpression-negative group. HGF expression was $21.0 \%$ in the c-Met-overexpression-positive group. Only one patient had peritoneal carcinomatosis in both HGF/c-Met-positive groups. The median survival was 19.6 \pm 7.4 months in the c-Met-overexpression-positive group and 23.3 \pm 3.0 months in the c-Met-overexpressionnegative group (Tables 2 and 3 ). There were no statistically significant differences in survival between the two groups $(P=0.711)$.

Survival was investigated in stages 1, 2, 3, and 4 c-Met overexpression groups. But all patients in stage 1 were alive and median survival was not reached in stage 2 , which could not be evaluated (Figure 3 ). The median survival was $15.1 \pm 3.1$ months in the c-Met-overexpression-positive stage 3
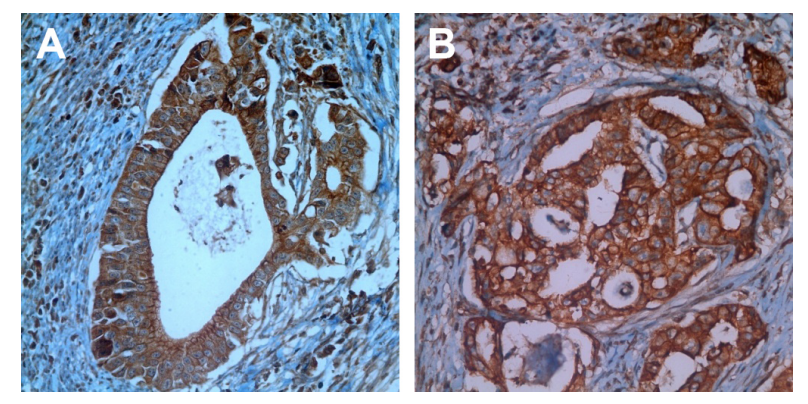

Figure 2 (A and B) Immunohistochemical staining using c-Met antibody showing $3(+)$ reaction in gastric cancer cells $(\times 40)$.
Table 3 Relationship between clinicopathological factors and c-Met overexpression in gastric cancers

\begin{tabular}{|c|c|c|c|}
\hline $\begin{array}{l}\text { Clinicopathological } \\
\text { factors }\end{array}$ & $\begin{array}{l}\text { c-Met } \\
\text { overexpression } \\
\text { positive, n (\%) } \\
(n=84)\end{array}$ & $\begin{array}{l}\text { c-Met } \\
\text { overexpression } \\
\text { negative, n (\%) } \\
(n=59)\end{array}$ & $P$-value \\
\hline Age (years) & 60 & 56 & 0.084 \\
\hline Sex & & & 0.462 \\
\hline Male & $59(70.2)$ & $38(64.4)$ & \\
\hline Female & $25(29.8)$ & $21(35.6)$ & \\
\hline Tumor location & & & 0.595 \\
\hline Proximal & $19(22.6)$ & $10(16.9)$ & \\
\hline Distal & $56(66.7)$ & $44(74.6)$ & \\
\hline Diffuse & $9(10.7)$ & $5(8.5)$ & \\
\hline Tumor differentiation & & & 0.636 \\
\hline Well & $10(11.9)$ & $6(10.2)$ & \\
\hline Moderate & $21(25.0)$ & $19(32.2)$ & \\
\hline Poor & $53(63.1)$ & $34(57.6)$ & \\
\hline Lauren classification & & & 0.387 \\
\hline Diffuse & $26(31.0)$ & $19(32.2)$ & \\
\hline Intestinal & $45(53.6)$ & $26(44.1)$ & \\
\hline Mix & $13(15.5)$ & $14(23.7)$ & \\
\hline Tumor stage (TNM) & & & $0.823^{\mathrm{a}}$ \\
\hline I & $6(7.1)$ & $3(5.1)$ & \\
\hline 2 & $14(16.7)$ & $8(13.6)$ & \\
\hline 3 & $34(40.5)$ & $28(47.5)$ & \\
\hline 4 & $30(35.7)$ & $20(33.9)$ & \\
\hline Distant metastasis & & & 0.823 \\
\hline Positive & $30(35.7)$ & $20(33.9)$ & \\
\hline Negative & $54(64.3)$ & $39(66.1)$ & \\
\hline Depth of invasion $(T)$ & $n=7 \mid$ & $n=49$ & $0.820^{\mathrm{a}}$ \\
\hline $\mathrm{pTI}$ & $5(7.0)$ & $2(4.1)$ & \\
\hline pT2 & $4(5.6)$ & $3(6.1)$ & \\
\hline PT3 & $15(21.1)$ & II (22.4) & \\
\hline pT4 & 47 (66.2) & $33(67.3)$ & \\
\hline \multicolumn{2}{|c|}{ Lymphovascular invasionn=7 I } & $n=49$ & 0.678 \\
\hline Positive & $62(87.3)$ & $44(89.8)$ & \\
\hline Negative & $9(12.7)$ & $5(10.2)$ & \\
\hline HER-2 expression & & & $0.014^{a}$ \\
\hline Negative & $48(57.1)$ & $45(76.3)$ & \\
\hline $1+$ & $16(19.0)$ & $7(11.9)$ & \\
\hline $2+$ & $9(10.7)$ & $5(8.5)$ & \\
\hline $3+$ & II (I3.I) & $2(3.4)$ & \\
\hline HGF expression & $n=81$ & $n=45$ & 0.896 \\
\hline Negative & $64(79.0)$ & $36(80.0)$ & \\
\hline Positive & $17(2 \mid .0)$ & $9(20.0)$ & \\
\hline \multirow[t]{2}{*}{ Survival (month) } & $n=59$ & $n=43$ & 0.711 \\
\hline & $19.6 \pm 7.4$ & $23.3 \pm 3.0$ & \\
\hline
\end{tabular}

Note: a Mann-Whitney U-test was used.

group and 17.2 \pm 5.8 months in the c-Met-overexpressionnegative stage 3 group (Figure 4). There were no statistically significant differences in survival between the two groups $(P=0.706)$. The median survival was $11.6 \pm 5.7$ months in the c-Met-overexpression-positive stage 4 group and 11.9 \pm 7.1 months in the c-Met-overexpression-negative stage 4 group (Figure 5). There were no statistically significant differences in survival between the two groups $(P=0.229)$. 


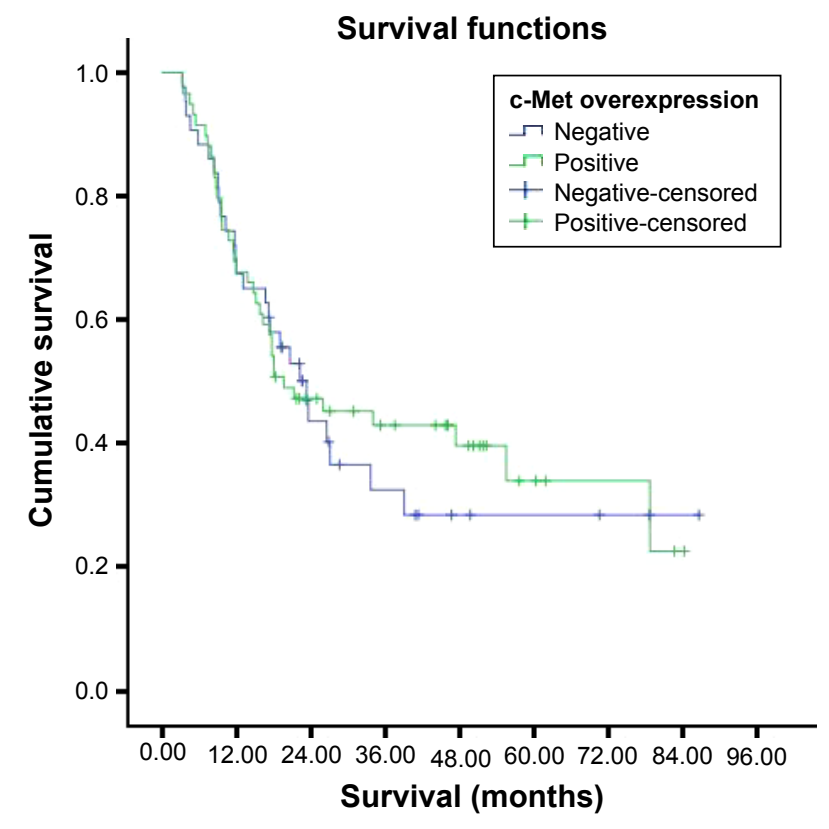

Figure 3 Survival curves of the patients according to c-Met expression.

\section{Hepatocyte growth factor}

The median survival was $20.6 \pm 4.0$ months in the HGFexpression-positive group $(\mathrm{n}=20)$ and $19.0 \pm 3.5$ months in the HGF-expression-negative group ( $\mathrm{n}=68$; Figures 6 and 7). No statistically significant differences in survival were found between the two groups $(P=0.863)$.

Survival was investigated in stages 1, 2, 3, and 4 HGF expression groups. But all patients in stage 1 were alive and median survival was not reached in stage 2 , which could not

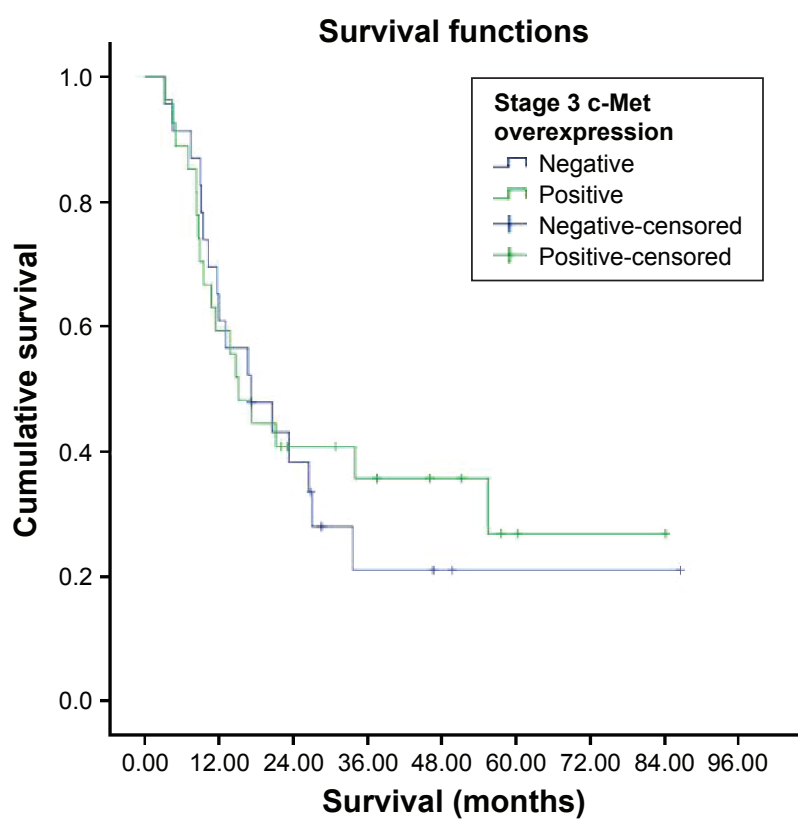

Figure 4 Survival curve for stage 3 c-Met overexpression groups.

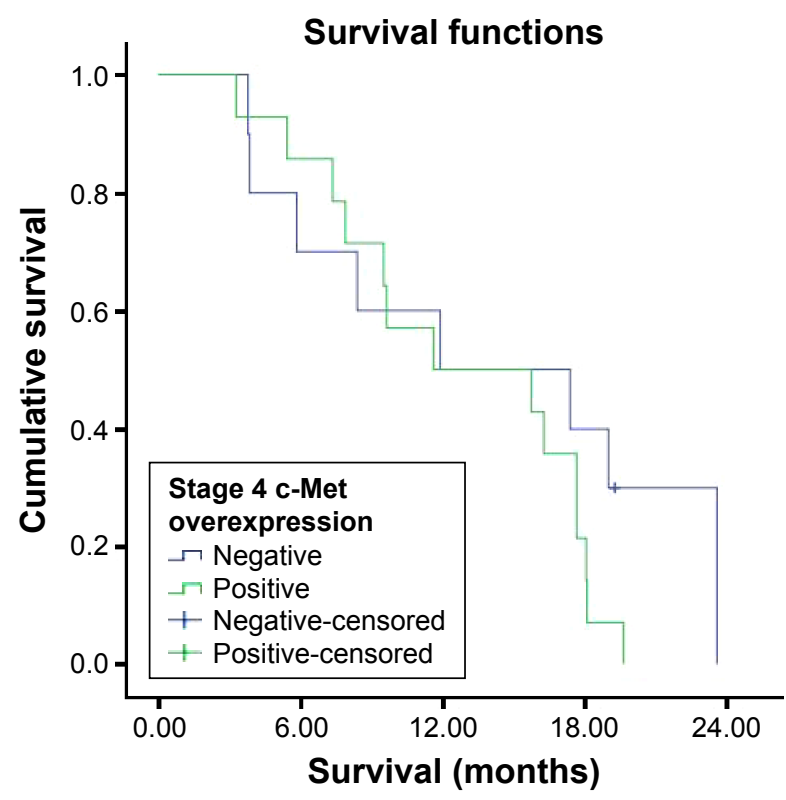

Figure 5 Survival curve for stage 4 c-Met overexpression groups.

be evaluated. The median survival was $20.6 \pm 6.7$ months in the HGF-expression-positive stage 3 group and 15.1 2 2.4 months in the HGF-expression-negative stage 3 group. There were no statistically significant differences in survival between the two groups $(P=0.753)$. The median survival was $17.4 \pm 8.2$ months in the HGF-expression-positive stage 4 group and 11.6 \pm 6.1 months in the HGF-expression-negative stage 4 group (Figures 8 and 9). There were no statistically significant differences in survival between the two groups $(P=0.719)$.

\section{HER-2 staining report}

Of the 143 gastric carcinoma tissue samples, $93(65.0 \%)$ were scored as $0,23(16.1 \%)$ as $1(+), 14(9.8 \%)$ as $2(+) 9$, and $13(9.1 \%)$ as $3(+)$, which indicated overexpression (Figure 10).

The HER-2 status was not associated with the sex, tumor location, distant metastases, depth of tumor invasion, and lymphovascular invasion $(P=0.061, P=0.144, P=0.063$,
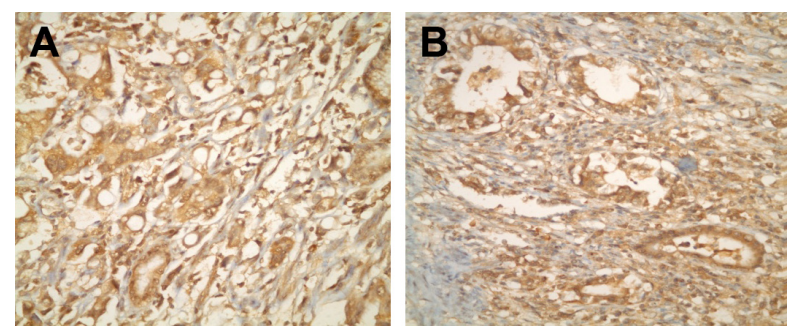

Figure 6 (A and B) Immunohistochemical staining using HGF antibody showing positive reaction in gastric cancer cells $(\times 40)$. Abbreviation: HGF, hepatocyte growth factor. 


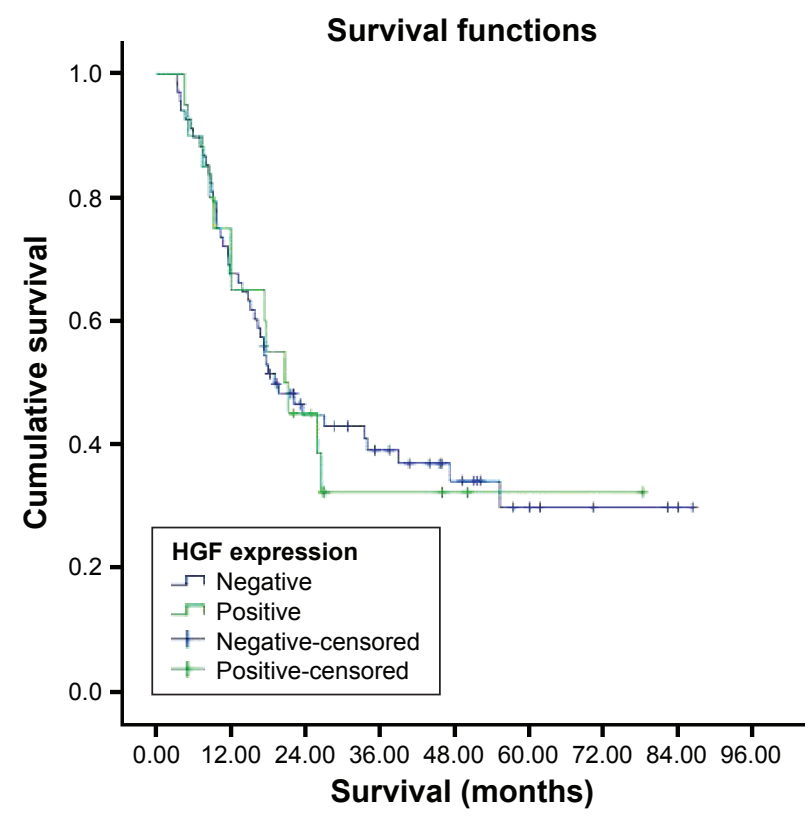

Figure 7 Survival curve for HGF expression groups.

Abbreviation: HGF, hepatocyte growth factor.

$P=0.776, P=1.000)$. The HER-2 status was associated with tumor differentiation, Lauren classification, and TNM ( $P=0.003, P=0.008$, and $P=0.045$ ). C-Met overexpression was $84.6 \%$ in the HER-2-overexpression-positive group and $56.2 \%$ in the HER-2-overexpression-negative group. The median survival was $18.1 \pm 5.2$ months in the HER-2overexpression-positive group and $22.2 \pm 4.1$ months in the HER-2-overexpression-negative group (Table 4). There were no statistically significant differences in survival between the two groups $(P=0.774)$.

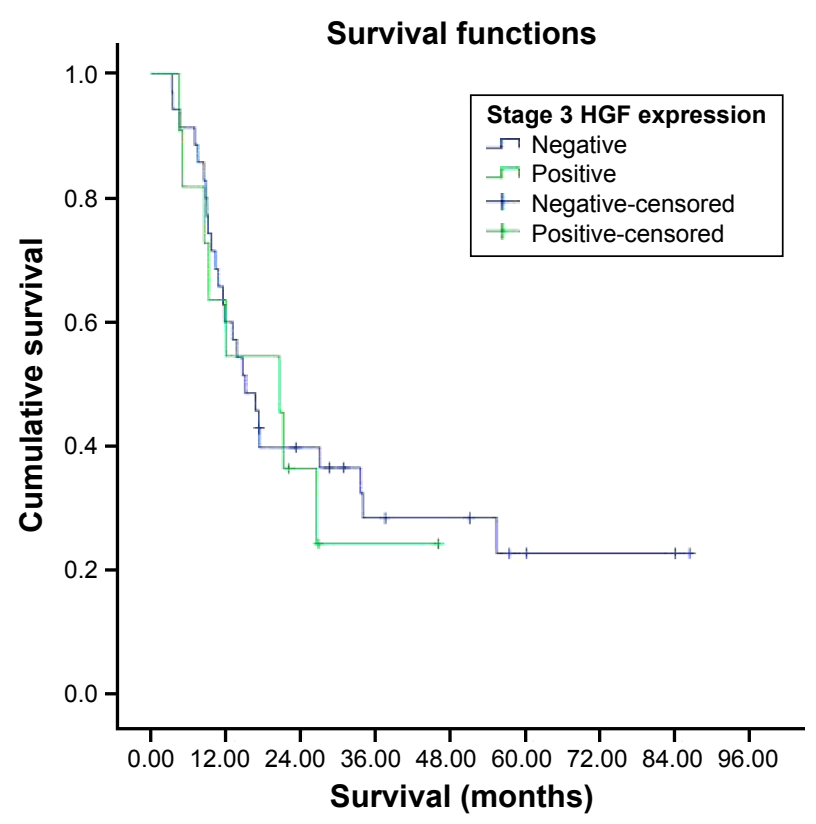

Figure 8 Survival curve for stage 3 HGF expression groups. Abbreviation: HGF, hepatocyte growth factor.

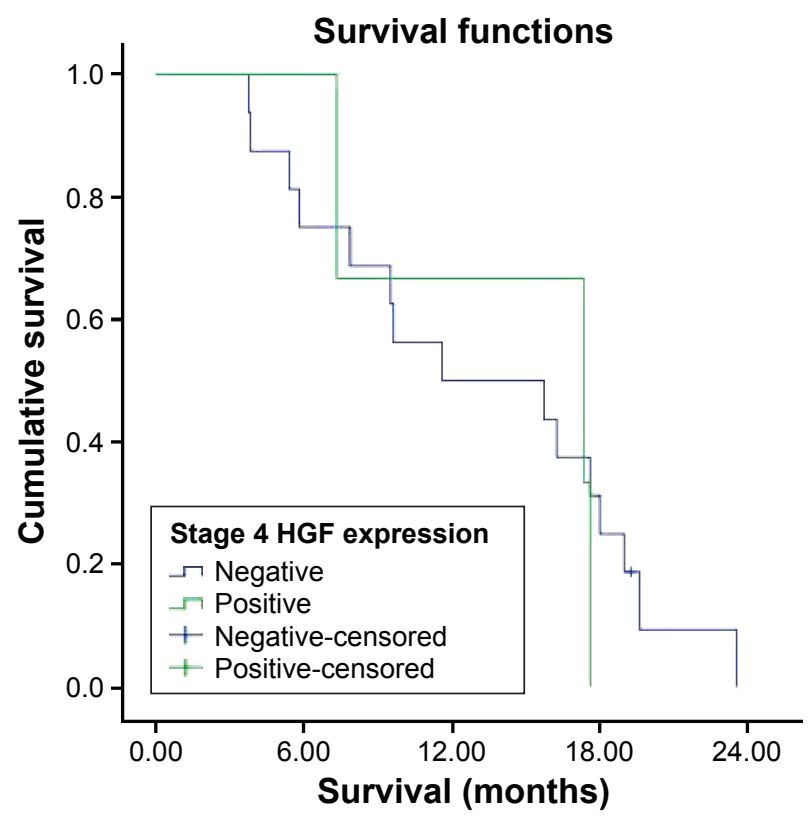

Figure 9 Survival curve for stage 4 HGF expression groups.

Abbreviation: HGF, hepatocyte growth factor.

Survival was investigated in stages $1,2,3$, and 4 HER-2 overexpression groups. But all patients in stage 1 survived, and there were not enough patients in stages 2 and 3; hence, survival could not be evaluated. The median survival was $11.6 \pm 6.3$ months in the HER-2-overexpressionpositive stage 4 group and 11.9 \pm 6.8 months in the HER-2overexpression-negative stage 4 group (Figures 11 and 12). There were no statistically significant differences in survival between the two groups $(P=0.969)$.

\section{Discussion and conclusion}

In this study, we aimed to determine the frequency of c-Met, HGF, and HER-2 overexpression, which play an important role in gastric cancer development, and their association with prognosis in terms of overall survival and other clinicopathological factors. The survival durations of the patients and patient subgroups are given in Table 5 .

c-Met expression was negative in $30.8 \%$ of patients and highly expressed in $58.7 \%$ of the patients. HER-2 expression

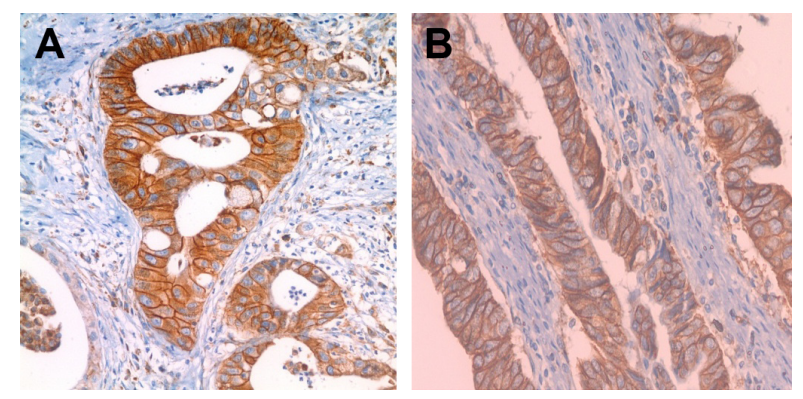

Figure 10 (A and B) Immunohistochemical staining using HER-2 antibody showing $3(+)$ reaction in gastric cancer cells $(\times 40)$. 
Table 4 Relationship between clinicopathological factors and HER-2 expression

\begin{tabular}{|c|c|c|c|}
\hline $\begin{array}{l}\text { Clinicopathological } \\
\text { factors }\end{array}$ & $\begin{array}{l}\text { HER-2 } \\
\text { overexpression } \\
\text { positive, n (\%) } \\
(n=13)\end{array}$ & $\begin{array}{l}\text { HER-2 } \\
\text { overexpression } \\
\text { negative, n (\%) } \\
(n=130)\end{array}$ & $P$-value \\
\hline Age (years) & $60.7 \pm 14.5$ & $57.0 \pm 12.9$ & 0.330 \\
\hline Sex & & & 0.061 \\
\hline Male & $12(92.3)$ & $85(65.4)$ & \\
\hline Female & I (7.7) & $45(34.6)$ & \\
\hline Tumor location & & & 0.144 \\
\hline Proximal & $5(38.5)$ & $24(18.5)$ & \\
\hline Distal & $8(61.5)$ & $92(70.8)$ & \\
\hline Diffuse & - & 14 (I0.8) & \\
\hline Tumor differentiation & & & 0.003 \\
\hline Well + moderate & $10(76.9)$ & $46(35.4)$ & \\
\hline Poor & $3(23.1)$ & $84(64.6)$ & \\
\hline Lauren classification & & & 0.008 \\
\hline Diffuse + mix & $2(15.4)$ & $70(53.8)$ & \\
\hline Intestinal & II (84.6) & $60(46.2)$ & \\
\hline Tumor stage (TNM) & & & $0.045^{\mathrm{a}}$ \\
\hline I & I (7.7) & $8(6.2)$ & \\
\hline 2 & - & $22(16.9)$ & \\
\hline 3 & $4(30.8)$ & $58(44.6)$ & \\
\hline 4 & $8(61.5)$ & $42(32.3)$ & \\
\hline Distant metastasis & & & 0.063 \\
\hline Positive & $8(6 \mid .5)$ & $42(32.3)$ & \\
\hline Negative & $5(38.5)$ & $88(67.7)$ & \\
\hline Depth of invasion $(T)$ & $n=8$ & $n=112$ & $0.776^{a}$ \\
\hline PTI & I (I2.5) & $6(5.4)$ & \\
\hline $\mathrm{pT} 2$ & - & $7(6.3)$ & \\
\hline pT3 & $2(25.0)$ & $24(21.4)$ & \\
\hline $\mathrm{pT} 4$ & $5(62.5)$ & $75(67.0)$ & \\
\hline \multicolumn{2}{|c|}{ Lymphovascular invasionn $=\mathbf{8}$} & $n=112$ & 1.000 \\
\hline Positive & $7(87.5)$ & $99(88.4)$ & \\
\hline Negative & $\mathrm{I}(12.5)$ & $13(11.6)$ & \\
\hline c-Met overexpression & & & 0.047 \\
\hline Positive & II (84.6) & $73(56.2)$ & \\
\hline Negative & $2(15.4)$ & $57(43.8)$ & \\
\hline \multirow[t]{2}{*}{ Survival (months) } & $n=8$ & $n=94$ & 0.774 \\
\hline & $18.1 \pm 5.2$ & $22.2 \pm 4.1$ & \\
\hline
\end{tabular}

Note: ${ }^{2}$ Mann-Whitney U-test was used.

was negative in $65 \%$ of the patients, whereas it was $2(+)$ in $9.8 \%$ and $3(+)$ in $9.1 \%$ of the patients. HGF was found to be positive only in $20.6 \%$ of the patients. In a previous study, Lee et $\mathrm{al}^{17}$ reported c-Met overexpression in $23.7 \%$ of 438 gastric cancer patients. In this study, c-Met protein expression was determined by IHC and scored according to membranous staining. In another study by Nakajima et $a 1,{ }^{8} \mathrm{c}-$ Met overexpression was $46.1 \%$ in 128 gastric cancer patients, whereas Retterspitz et al ${ }^{6}$ reported c-Met overexpression to be $48.9 \%$ in 94 gastric cancer patients. In this study, c-Met protein expression was determined by IHC and scored by cytoplasmic staining. In a study by Drebber et al, ${ }^{7} \mathrm{c}-$ Met overexpression was detected to be $73.7 \%$ in 114 gastric cancer patients.

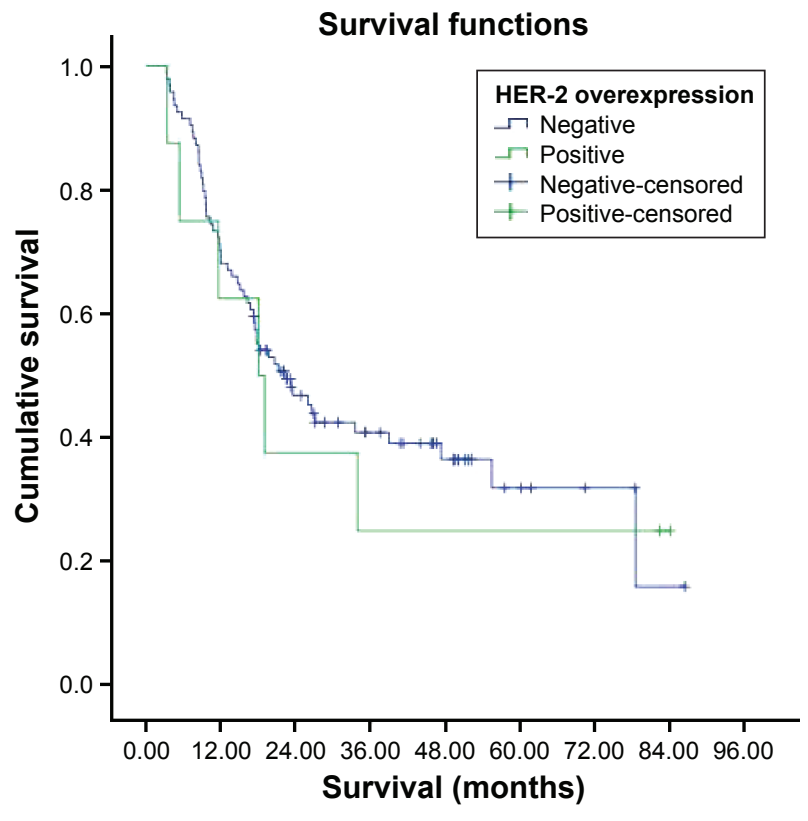

Figure I I Survival curve for HER-2 overexpression groups.

In this study, c-Met protein expression was determined by IHC and scored by both membranous and cytoplasmic staining. In our study, c-Met overexpression was $58.7 \%$ in 125 patients. The literature reports a difference in the frequency of c-Met overexpression in gastric cancer. This difference may be caused by the different methods used for c-Met expression. In our study, we used both membranous and cytoplasmic staining for c-Met expression, and accordingly, we have created a scoring system as given in Table 1. Some studies used only cytoplasmic staining, only membranous staining,

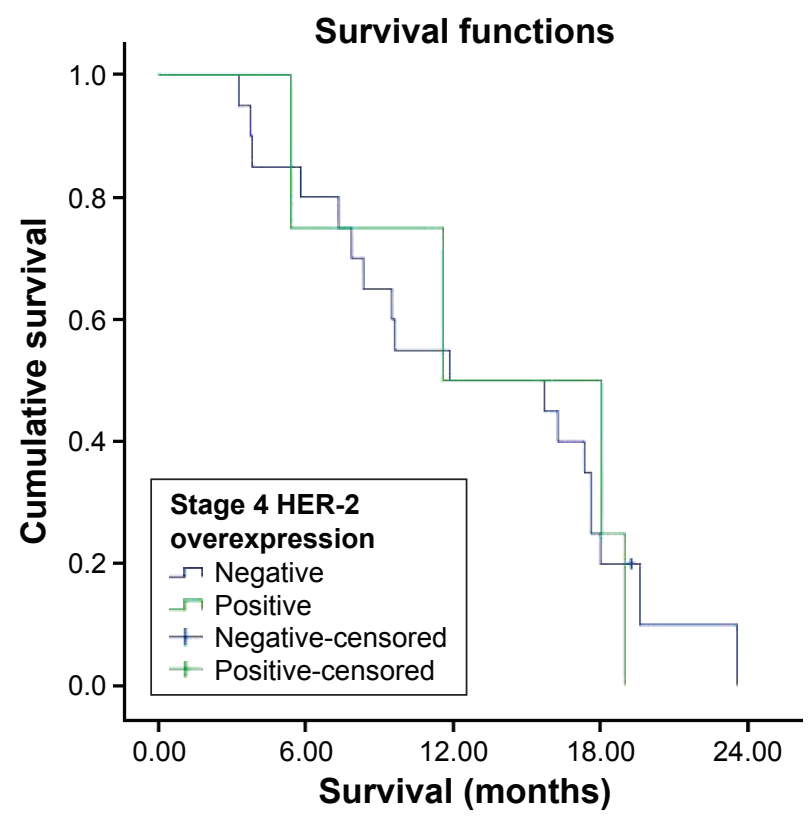

Figure 12 Survival curve for stage 4 HER-2 overexpression groups. 
Table 5 Median overall survival of the patients and patient subgroups

\begin{tabular}{lll}
\hline & $\begin{array}{l}\text { Overall survival } \\
\text { (months) }\end{array}$ & $\begin{array}{l}\text { 95\% confidence } \\
\text { interval }\end{array}$ \\
\hline $\begin{array}{l}\text { All patients }(\mathrm{n}=102) \\
\text { c-Met }\end{array}$ & 21.2 & $13.9-28.6$ \\
$\quad$ Positive $(\mathrm{n}=59)$ & 19.6 & $5.0-34.2$ \\
Negative $(\mathrm{n}=43)$ & 23.3 & $17.4-29.2$ \\
Stage 3(+) & 15.1 & $9.1-21.1$ \\
Stage 3(-) & 17.2 & $5.7-28.6$ \\
Stage 4(+) & 11.6 & $0.4-22.8$ \\
Stage 4(-) & 11.9 & $0-25.8$ \\
HGF & & \\
Positive $(n=20)$ & 20.6 & $12.7-28.5$ \\
Negative $(n=68)$ & 19.0 & $12.2-25.8$ \\
Stage 3(+) & 20.6 & $7.5-33.6$ \\
Stage 3(-) & 15.1 & $10.3-19.9$ \\
Stage 4(+) & 17.4 & $1.3-33.4$ \\
Stage 4(-) & 11.6 & $0-23.6$ \\
HER-2 & & \\
Positive & 18.1 & $7.8-28.3$ \\
Negative & 22.2 & $14.2-30.2$ \\
Stage 4(+) & 11.6 & $0-24.0$ \\
Stage 4(-) & 11.9 & $0-25.2$ \\
\hline Abreviation &
\end{tabular}

Abbreviation: HGF, hepatocyte growth factor.

or both, showing c-Met expression in the literature. Furthermore, different studies used different criteria for scoring. Therefore, investigation of c-Met expression by IHC methods definitely warrants standard scoring criteria and we believe that our scoring system proposed by Sokmensuer as given in Table 1 seems to be the optimal one. Besides the scoring system, there is also controversy about the correlation with c-Met overexpression and clinicopathological variables in the literature. In the study by Nakajima et al, ${ }^{8}$ overexpression of c-Met was correlated with depth of tumor invasion and lymph node metastasis. The survival rate of patients with c-Met overexpression $(+)$ gastric cancer was poorer than that of patients with gastric cancers with no overexpression. In the study by Janjigian et al, ${ }^{9}$ positive c-Met staining with IHC was associated with Lauren intestinal histology. In the study by Retterspitz et al, ${ }^{6} \mathrm{c}$-Met overexpression was not associated with any clinicopathological factors such as Lauren or WHO classification, depth of invasion, nodal metastasis, TNM stage, and grade. In another study by Drebber et al, ${ }^{7}$ c-Met overexpression was not associated with any clinicopathological factors such as age, sex, Lauren and WHO classification, differentiation, and TNM stage. In the study by Toiyama et al, ${ }^{10}$ increased HGF and c-Met had a significant association with poor prognosis and predicted peritoneal dissemination. In our study, there was no statistically significant difference in age, sex, tumor location, differentiation, Lauren classification, TNM staging, presence of distant metastasis, depth of tumor invasion ( $\mathrm{T}$ ), lymphovascular invasion, and survival between c-Met subgroups. Coexpression of HGF/cMet was observed in 17 patients and only one patient had peritoneal carcinomatosis in our study.

In the study by Cirne-Lima et al, ${ }^{18}$ HER-2 positivity was $5.4 \%$ in 37 gastric cancer patients. In the study by $\mathrm{Xu}$ et al,${ }^{19}$ HER-2 overexpression was $11.9 \%$ in 126 gastric cancer patients. In this study, the IHC score was determined according to the ToGA trial, and HER-2 positivity status was defined as $\mathrm{IHC} 3+$ or $\mathrm{IHC} 2+$ plus gene-amplified. Geng et al, ${ }^{20}$ and Ismail et al, ${ }^{21}$ reported HER-2 positivity to be $19.1 \%$ and $25.8 \%$, respectively. In their study, samples with scores $2+$ or $3+$ were considered to be HER- 2 positive. In our study, HER-2 3(+) staining was $9.1 \%$ by the IHC method. This result seems to be consistent with the figures reported in the current literature. Unfortunately, in our study HER-2 2+/equivocal score could not be confirmed with fluorescence in situ hybridization (FISH) testing. Therefore, overexpression might have been higher if FISH test was applied.

In the study by Zhou et al, ${ }^{22}$ HER-2 overexpression was closely correlated with the Lauren type, degree of differentiation, tumor size, and lymph node metastasis. In the study by $\mathrm{Xu}$ et al, ${ }^{19}$ HER-2 was significantly associated with improved disease-free survival. In the study by Geng et al, HER-2 overexpression in primary tumor correlated with lymph node metastasis, distant metastasis, and AJCC stage. Patients with HER-2 positivity had poor survival. ${ }^{20}$ In our study, the HER-2 status was associated with tumor differentiation, Lauren classification, and TNM stage. The HER-2 status was not associated with the sex, tumor location, distant metastases, depth of tumor invasion, and lymphovascular invasion.

ToGA clinical trial showed that the humanized monoclonal antibody against HER-2, trastuzumab (Herceptin), could effectively prolong overall survival and progression-free survival and increases the response rate in HER-2-positive advanced gastric carcinoma. ${ }^{11}$ The use of trastuzumab for HER-2-positive patients is routinely recommended for the treatment of advanced gastric cancer. ${ }^{23}$ Certainly new molecular targets are needed that can be targeted for the treatment of HER-2-negative patients. In our study, c-Met overexpression was $56.2 \%$ in HER-2-overexpression-negative group. Unfortunately, targeting c-Met has been disappointing for the treatment of patients with advanced gastric cancer. If new molecular targets are indentified that have a role in tumor growth and survival, then better molecular classification of gastric cancer and new treatments options for this disease may be developed. 


\section{Disclosure}

The authors report no conflicts of interest in this work.

\section{References}

1. Yalcin S. Gastric cancer in Turkey-a bridge between west and East. Gastrointest Cancer Res. 2009;3(1):29-32.

2. Nagini S. Carcinoma of the stomach: a review of epidemiology, pathogenesis, molecular genetics and chemoprevention. World J Gastrointest Oncol. 2012;4(7):156-169.

3. Morishita A, Gong J, Masaki T. Targeting receptor tyrosine kinases in gastric cancer. World J Gastroenterol. 2014;20(16):4536-4545.

4. Yu S, Yu Y, Zhao N, Cui J, Li W, Liu T. C-Met as a prognostic marker in gastric cancer: a systematic review and meta-analysis. PLoS One. 2013;8(11):e79137.

5. Christensen JG, Burrows J, Salgia R. c-Met as a target for human cancer and characterization of inhibitors for therapeutic intervention. Cancer Lett. 2005;225(1):1-26.

6. Retterspitz MF, Mönig SP, Schreckenberg S, et al. Expression of \{beta $\}$ catenin, MUC1 and c-met in diffuse-type gastric carcinomas: correlations with tumour progression and prognosis. Anticancer Res. 2010; 30(11):4635-4641.

7. Drebber U, Baldus SE, Nolden B, et al. The overexpression of c-met as a prognostic indicator for gastric carcinoma compared to p53 and p21 nuclear accumulation. Oncol Rep. 2008;19(6): 1477-1483.

8. Nakajima M, Sawada H, Yamada Y, et al. The prognostic significance of amplification and overexpression of c-met and c-erb B-2 in human gastric carcinomas. Cancer. 1999;85(9):1894-1902.

9. Janjigian YY, Tang LH, Coit DG, et al. MET expression and amplification in patients with localized gastric cancer. Cancer Epidemiol Biomarkers Prev. 2011;20(5):1021-1027.

10. Toiyama Y, Yasuda H, Saigusa S, et al. Co-expression of hepatocyte growth factor and c-Met predicts peritoneal dissemination established by autocrine hepatocyte growth factor/c-Met signaling in gastric cancer. Int J Cancer. 2012;130(12):2912-2921.

11. Hu B, El Hajj N, Sittler S, Lammert N, Barnes R, Meloni-Ehrig A. Gastric cancer: classification, histology and application of molecular pathology. J Gastrointest Oncol. 2012;3(3):251-261.
12. Akiyama T, Sudo C, Ogawara H, Toyoshima K, Yamamoto T. The product of the human c-erbB-2 gene: a 185-kilodalton glycoprotein with tyrosine kinase activity. Science. 1986;232(4758):1644-1646.

13. Wang SC, Hung MC. HER2 overexpression and cancer targeting. Semin Oncol. 2001;28(5 suppl 16):115-124.

14. Koeppen HK, Wright BD, Burt AD, et al. Overexpression of HER2/ neu in solid tumours: an immunohistochemical survey. Histopathology. 2001;38(2):96-104.

15. Movagharnejad K, Sharbatdaran M, Sheffaee S, Kashifard M, Sedaghat S. HER-2/neu marker examination using immunohistochemical method in patients suffering from gastric adenocarcinoma. Int $\mathrm{J} \mathrm{Mol}$ Cell Med. 2013;2(4):199-203.

16. Hofmann M, Stoss O, Shi D, et al. Assessment of a HER2 scoring system for gastric cancer: results from a validation study. Histopathology. 2008;52:797-805.

17. Lee HE, Kim MA, Lee HS, et al. MET in gastric carcinomas: comparison between protein expression and gene copy number and impact on clinical outcome. Br J Cancer. 2012;107(2):325-333.

18. Cirne-Lima FK, Rosa Ade S, Kulczynski JM, Mattana DS, Corezolla K, Moreira LF. Immunohistochemical expression of HER-2/ NEU-CERBB-2 in patients with adenocarcinoma of the stomach. Rev Col Bras Cir. 2009;36(2):131-134.

19. Xu CC, Yue L, Wei HJ, et al. Significance of TFF3 protein and Her-2/neu status in patients with gastric adenocarcinoma. Pathol Res Pract. 2013; 209(8):479-485.

20. Geng Y, Chen X, Qiu J, et al. Human epidermal growth factor receptor-2 expression in primary and metastatic gastric cancer. Int JClin Oncol.2014; 19(2):303-311.

21. Ismail HM, Moneer M, El-Baradie M, Khorshid O, Touny A. Clinicopathologic and prognostic significance of overexpression of her-2/ neu and $\mathrm{p} 53$ oncoproteins in gastric carcinoma using tissue microarray. J Egypt Natl Canc Inst. 2007;19(2):147-157.

22. Zhou F, Li N, Jiang W, et al. Prognosis significance of HER-2/neu overexpression/amplification in Chinese patients with curatively resected gastric cancer after the ToGA clinical trial. World J Surg Oncol. 2012;10:274

23. American Joint Commitee on Cancer (AJCC). TNM Staging Classification for Carcinoma of the Stomach. 7th ed. Springer New York Dordrecht Heidelberg London; 2010.
OncoTargets and Therapy

\section{Publish your work in this journal}

OncoTargets and Therapy is an international, peer-reviewed, open access journal focusing on the pathological basis of all cancers, potential targets for therapy and treatment protocols employed to improve the management of cancer patients. The journal also focuses on the impact of management programs and new therapeutic agents and protocols on

\section{Dovepress}

patient perspectives such as quality of life, adherence and satisfaction. The manuscript management system is completely online and includes a very quick and fair peer-review system, which is all easy to use. Visit http://www.dovepress.com/testimonials.php to read real quotes from published authors. 